\title{
Genetic Characterization of Genetic Resources of Aegilops tauschii, Wheat D Genome Donor, Newly Collected in North Caucasia
}

\author{
Ayaka Kakizaki', Taihachi Kawahara ${ }^{2}$, Mikhail Alexandrovich Zhuk ${ }^{3}$, \\ Tamara Nikolaevna Smekalova ${ }^{3}$, Kazuhiro Sato ${ }^{4}$, Toshinori Abe ${ }^{1}$, Tsuneo Sasanuma ${ }^{*}$ \\ ${ }^{1}$ Laboratory of Plant Genetics and Breeding, Faculty of Agriculture, Yamagata University, Tsuruoka, Japan \\ ${ }^{2}$ Graduate School of Agriculture, Kyoto University, Muko, Japan \\ ${ }^{3}$ N.I. Vavilov Research Institute of Plant Industry, St. Petersburg, Russia \\ ${ }^{4}$ Institute of Plant Science and Resources, Okayama University, Kurashiki, Japan \\ Email: *sasanuma@tds1.tr.yamagata-u.ac.jp
}

How to cite this paper: Kakizaki, A., Kawahara, T., Zhuk, M.A., Smekalova, T.N., Sato, K., Abe, T. and Sasanuma, T. (2017) Genetic Characterization of Genetic Resources of Aegilops tauschii, Wheat D Genome Donor, Newly Collected in North Caucasia. American Journal of Plant Sciences, 8, 2769-2784.

https://doi.org/10.4236/ajps.2017.811187

Received: August 31, 2017

Accepted: October 21, 2017

Published: October 24, 2017

Copyright (C) 2017 by authors and Scientific Research Publishing Inc. This work is licensed under the Creative Commons Attribution International License (CC BY 4.0).

http://creativecommons.org/licenses/by/4.0/

\begin{abstract}
For the purpose of broadening the available genetic resources to improve wheat breeding and to elucidate wheat evolution, 16 accessions of Aegilops tauschii newly collected in North Caucasia named NCT accessions were characterized genetically based on morphology, chloroplast SSR variation and AFLP. Ae. tauschii is one of the most important wild wheat genetic resources because it is the progenitor of the $\mathrm{D}$ genome of hexaploid wheat. Since Caucasia is considered to be a center of diversity of both cultivated and wild wheat, a lot of studies have been conducted to evaluate the diversity of Caucasian genetic resources including Ae. tauschii. Such kind of analyses, however, focused on Transcaucasia but little attention has been paid to North Caucasia because of the lack of available genetic resources. Based on the molecular analyses in this study, the $16 \mathrm{NCT}$ accessions were generally divided into two groups although morphologically those are classified into the same subspecies. The grouping also represented geographical distribution, that is, the northern part group and Derbent group. This division is consistent with the two major genepools in Ae tauschii reported in previous studies. The northern part and Derbent groups correspond to Eurasian wide genepool (called Tauschii genepool) and Caucasia and Caspian coast limited genepool (Strangulata genepool), respectively. Regarding to chloroplast, all the 16 accessions were genotyped as HG7, the most major haplogroup of the species. Although all the 16 NCT accessions were categorized into ssp. tauschii morphologically, accessions of Derbent group showed a tendency to have larger spikelets. Among
\end{abstract}


them, especially NCT3 had the quite large size of spikelets and grains that are at almost the largest level in ssp. tauschii. The results of this study filled the missing information of Ae. tauschii and will be helpful for future utilization.

\section{Keywords}

Aegilops tauschii, North Caucasia, Spikelet Morphology, Chloroplast SSR, AFLP

\section{Introduction}

The most cultivated wheat Triticum aestivum L. has the A, B and D genomes that has originated in the interspecific hybridization followed by polyploidization between tetraploid Emmer wheat T. turgidum L. and Aegilops tauschii Coss. [1] [2]. Ae. tauschii is a wild diploid goatgrass species with the DD genome and considered to be one of the most important genetic resources among wheat wild relatives because of its donation of the $\mathrm{D}$ genome to bread wheat. Ae. tauschii is distributing from Syria to western China throughout central part of Eurasian continent and inhabits various environmental conditions in dry grasslands, fallow, steppes, roadsides, woodlands, marginal forests and stony slopes, and even can be found in irrigated field and river valleys [3]. Several studies revealed the high level of genetic diversity of Ae. tauschii regarding several useful traits, i.e., seed storage protein [4], flowering time [5], disease resistance [6] and biotic and abiotic stress tolerance [7] [8], suggesting the usefulness for improvement of wheat production.

Based on spike morphology, Ae. tauschii is divided into two subspecies, ssp. tauschii, and ssp. strangulata [9] [10]. Subspecies tauschii has vertically elongated rectangle glumes and internodes between spikelets are not much constricted, on the other hand ssp. strangulata has square or wide glumes and its internodes are markedly constricted. Subspecies tauschii is widely distributing throughout Eurasian continent, whereas ssp. strangulata has a restricted distribution in Caucasia and coastal region of Caspian Sea in northern Iran.

Because of its importance in wheat genetics and breeding, the diversity of $A e$. tauschii has been studied extensively using various techniques, that is, isozyme [11] [12] [13], RFLP [14], chloroplast SSR [15] [16], AFLP [17] [18] and DNA array [19] [20] [21]. Based on RFLP, Dvorak et al. (1998) reported that Ae. tauschii could be divided into two genepools namely Tauschii and Strangulata [14]. This molecular-based classification is not completely consistent with the morphological one. The Strangulata genepool consists of morphology-based ssp. strangulata and some accessions of ssp. tauschii collected in Caucasia and Caspian coastal region in Iran. Tauschii genepool includes all other ssp. tauschii accessions covering the entire species distribution including the area where accessions of Strangulata genepool inhabit. The subsequent nuclear DNA-based molecular 
analyses supported the division of two genepools and added the evidence for presence of the third minor groups limitedly distributing in Georgia. Sohail et al. (2012) reported the two major groups A and C that are corresponding to Tauschii and Strangulata genepools in Dvorak et al. (1998), respectively, and the minor third group B [19]. Contrary to the nuclear DNA-based analyses, Matsuoka et al. (2009) revealed that the Ae. tauschii genepool are classified into 18 haplogroups based on sequencing of chloroplast SSR loci [16]. The classification based on nuclear and chloroplast DNAs are not consistent with each other. The most major chloroplast haplogroup HG7 contains accessions collected in entire distribution areas, and both genepools are included in this major chloroplast haplogroup.

Caucasia, the area lying between Black Sea and Caspian Sea, is an important place in wheat science because the area is a candidate of the origin of bread wheat and one of the centers of diversity for both cultivated and wild wheat. As mentioned above, Caucasia is also important for Ae. tauschii since it is the area where both genepools distribute, therefore can be regarded as a center of diversity of this species [14] [16]. Thus there are several previous studies intensively using Caucasian Ae. tauschii, but they focused on mainly Transcaucasia but not on North Caucasia. Caucasia is generally separated into two regions, that is, Transcaucasia consisting of Georgia, Armenia and Azerbaijan on the south side of the Great Caucasus Mountains with altitude above 5000 m, and North Caucasia that is the Russian territory on the north of the mountains. The plants in these two regions may be generically differentiated because of the geographical isolation by high mountains. There are some accessions in genebank collected in North Caucasia, for example, KU20-1 used in several previous studies [16] [18] [19] that is the firstly numbered accession of Ae. tauschii in Kyoto University collection probably provided from Dr. Vavilov to Dr. Kihara before World War II, but number of accessions are limited. Unique genetic resources are possibly discovered in North Caucasia since it is a margin of the center of diversity of $A e$. tauschii. To elucidate the genetic diversity of Ae. tauschii, the investigation using a set of considerable number of the North Caucasian materials is important.

In this study, we conducted genetic characterization of 16 accessions of Ae. tauschii that we newly collected in North Caucasia supported by the international exchange program between Japan and Russia (Figure 1). Here we called these materials NCT, meaning North Caucasian Ae. tauschii. The 16 NCT accessions were collected from Stavropol Province, the northern part of North Caucasia to Derbent the second biggest city in Dagestan Republic in the Russian Federation located in the southern border with Azerbaijan on western coast of Caspian Sea. We evaluated the genetic diversity of these genetic resources based on morphological traits and two molecular techniques chloroplast SSR and AFLP that was used as a tool detecting the nuclear-based DNA variation. Based on the results obtained, the features of the North Caucasian Ae. tauschii are discussed. 


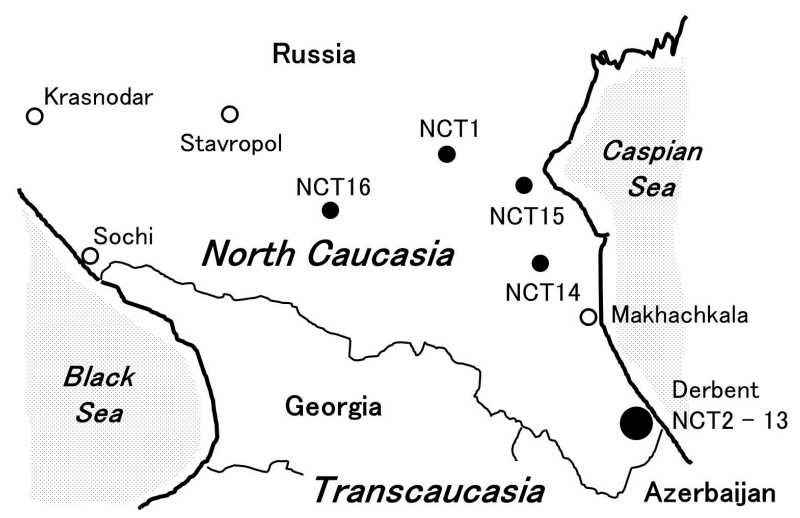

(a)

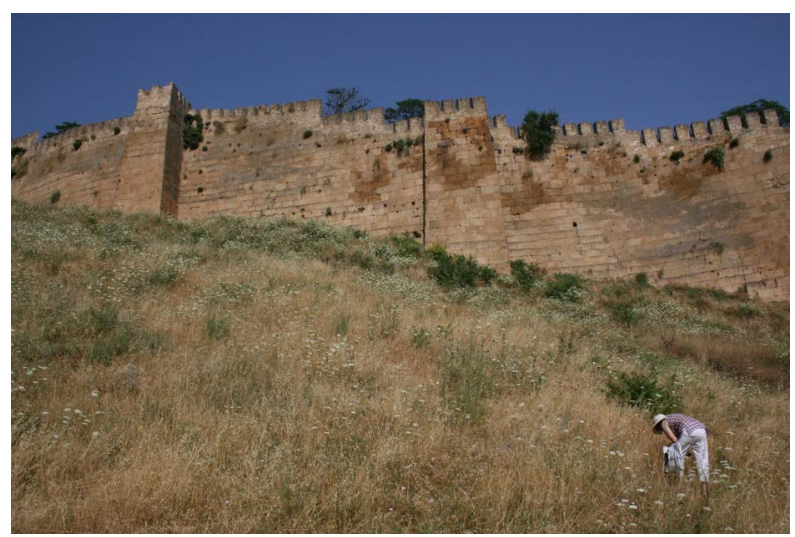

(b)

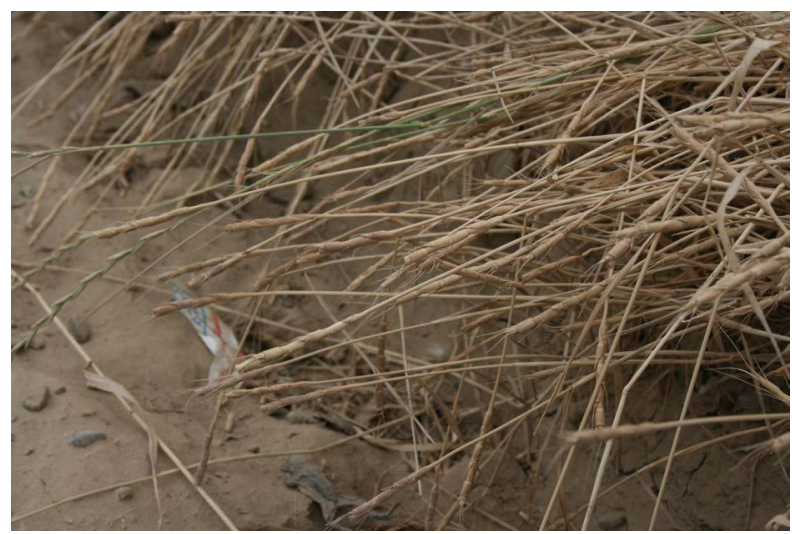

(c)

Figure 1. Collection site of the North Caucasian Ae. tauschii. (a) Map of the sites, (b) Natural habitat of Aegilops species including Ae. tauschii covering the slope of the world heritage Derbent Citadel and, (c) the naturally growing Ae. tauschii on the roadside in Derbent.

\section{Materials and Methods}

\subsection{Plant Materials}

Totally 39 accessions of Ae. tauschii were used in this study. Among them 16 accessions were NCT (North Caucasian Ae. tauschii) accessions collected in North Caucasia by the international exchange program between Japan and Russia, in 
June-July 2010. The other 23 accessions were provided from National BioResources Project (NBRP) KOMUGI maintained in Kyoto University, Japan (numbered as KU), and International Center for Agricultural Research in Dry Areas (ICARDA) (numbered as IG). These 23 accessions were selected to cover general entire genetic variation of the species in consideration of geographical distribution, morphological classification, and genetic diversity on nuclear DNA reported by Sohail et al. (2012) [19]. The passport data of the accessions are shown in Table 1 and Table 2. For molecular analyses, T. aestivum cv. Chinese Spring and an accession of Ae. caudata (KU6-1), the CC genome diploid, were used as reference and outgroup.

\subsection{Investigation of Morphological Characters}

The morphological characters of original specimens collected in North Caucasia were investigated. Glume length (GL), glume width (GW), glume height, spikelet length, awn length, grain length, grain width were measured. Five spikelets were investigated for each accession. Since the spikes were shattered at the harvesting time, the positions of the measured spikelets in the spikes were unknown. We chose seemingly well matured large size spikelets. As for qualitative traits, hairiness of glumes and color of spikelets were checked.

\subsection{Genotyping of Chloroplast SSR Loci and IGS Region}

Total DNA of the NCT accessions were extracted from leaves using CTAB

Table 1. Passport data of 16 accessions of Ae. tauschii collected in North Caucasia.

\begin{tabular}{ccccc}
\hline Accession Number & Location & Latitude (N) & Longitude (E) & Altitude (m) \\
\hline NCT1 & Stavropol Province & $44^{\circ} 27^{\prime \prime}$ & $045^{\circ} 19^{\prime \prime}$ & 18 \\
NCT2 & Derbent, Dagestan & $41^{\circ} 59^{\prime \prime}$ & $048^{\circ} 17^{\prime \prime}$ & 133 \\
NCT3 & Derbent, Dagestan & $42^{\circ} 00^{\prime \prime}$ & $048^{\circ} 17^{\prime \prime}$ & 216 \\
NCT4 & Derbent, Dagestan & $42^{\circ} 01^{\prime \prime}$ & $048^{\circ} 15^{\prime \prime}$ & 554 \\
NCT5 & Derbent, Dagestan & $42^{\circ} 01^{\prime \prime}$ & $048^{\circ} 15^{\prime \prime}$ & 686 \\
NCT6 & Derbent, Dagestan & $41^{\circ} 59^{\prime \prime}$ & $048^{\circ} 18^{\prime \prime}$ & 13 \\
NCT7 & Derbent, Dagestan & $42^{\circ} 03^{\prime \prime}$ & $048^{\circ} 16^{\prime \prime}$ & 152 \\
NCT8 & Derbent, Dagestan & $42^{\circ} 02^{\prime \prime}$ & $048^{\circ} 15^{\prime \prime}$ & 348 \\
NCT9 & Derbent, Dagestan & $41^{\circ} 56^{\prime \prime}$ & $048^{\circ} 09^{\prime \prime}$ & 301 \\
NCT10 & Derbent, Dagestan & $41^{\circ} 57^{\prime \prime}$ & $048^{\circ} 06^{\prime \prime}$ & 575 \\
NCT11 & Derbent, Dagestan & $41^{\circ} 58^{\prime \prime}$ & $048^{\circ} 02^{\prime \prime}$ & 592 \\
NCT12 & Derbent, Dagestan & $42^{\circ} 01^{\prime \prime}$ & $048^{\circ} 02^{\prime \prime}$ & 438 \\
NCT13 & Derbent, Dagestan & $41^{\circ} 59^{\prime \prime}$ & $048^{\circ} 19^{\prime \prime}$ & -2 \\
NCT14 & Northern Dagestan & $43^{\circ} 41^{\prime \prime}$ & $046^{\circ} 42^{\prime \prime}$ & -9 \\
NCT15 & Northern Dagestan & $44^{\circ} 25^{\prime \prime}$ & $046^{\circ} 30^{\prime \prime}$ & -36 \\
NCT16 & Stavropol Province & $44^{\circ} 13^{\prime \prime}$ & $043^{\circ} 32^{\prime \prime}$ & 232 \\
\hline & & & \\
\hline
\end{tabular}


Table 2. Accessions used in AFLP analysis.

\begin{tabular}{|c|c|c|c|c|}
\hline Country & Accession & Subspecies & Variety & Sohail et al. $(2012)^{\mathrm{a}}$ \\
\hline Dagestan $(n=1)$ & KU20-1 & tauschii & typica & $\mathrm{C}$ \\
\hline Georgia $(n=1)$ & KU2829A & tauschii & typica & B \\
\hline Azerbaijan $(\mathrm{n}=1)$ & KU2806 & tauschii & typica & $\mathrm{C}$ \\
\hline Armenia $(\mathrm{n}=1)$ & KU2809 & tauschii & anathera & A \\
\hline Syria $(\mathrm{n}=1)$ & IG46623 & tauschii & typica & $\mathrm{C}$ \\
\hline Turkey $(\mathrm{n}=1)$ & KU2132 & tauschii & typica & A \\
\hline \multirow[t]{10}{*}{$\operatorname{Iran}(n=10)$} & KU20-10 & tauschii & meyeri & $\mathrm{C}$ \\
\hline & KU2109 & tauschii & meyeri & A \\
\hline & KU2144 & tauschii & typica & A \\
\hline & KU20-8 & tauschii & typica & $\mathrm{C}$ \\
\hline & KU2157 & tauschii & typica & - \\
\hline & KU2159 & tauschii & typica & $\mathrm{C}$ \\
\hline & KU2074 & strangulata & strangulata & $\mathrm{C}$ \\
\hline & KU2076 & strangulata & strangulata & $\mathrm{C}$ \\
\hline & KU2088 & strangulata & strangulata & $\mathrm{C}$ \\
\hline & KU2096 & strangulata & strangulata & $\mathrm{C}$ \\
\hline \multirow[t]{5}{*}{ Afghanistan $(n=5)$} & KU2059 & tauschii & anathera & - \\
\hline & KU2636 & tauschii & anathera & A \\
\hline & KU2012 & tauschii & typica & - \\
\hline & KU2022 & tauschii & typica & $\mathrm{A}$ \\
\hline & KU2039 & tauschii & - & B \\
\hline Uzbekistan $(\mathrm{n}=1)$ & KU20-3 & tauschii & typica & - \\
\hline China $(\mathrm{n}=1)$ & IG48976 & tauschii & - & - \\
\hline
\end{tabular}

a: A, B and C mean to the clusters in Sohail et al. (2012). A and C correspond to the Tauschii and Strangulata genepool, respectively, and B is the third minor cluster.

method [22]. According to Matsuoka et al. $(2005,2009)$ [15] [16], nine chloroplast SSR loci (WCt1, 4, 5, 6, 8, 10, 12, 17 - 18 and 24) that demonstrated interspecific repeat number variation in Ae. tauschii and two chloroplast intergenic spacer regions $(\operatorname{trn} T-L$ and $\operatorname{trnL}-F)$ that showed interspecific nucleotide polymorphisms in Ae. tauschii were amplified by PCR. The primer sequences used in this study followed the Ishii et al. (2001) [23] and Taberlet et al. (1991) [24] in which the markers had been originally developed. The PCR condition was 25 cycles of $1 \mathrm{~min}$ at $94^{\circ} \mathrm{C}, 1 \mathrm{~min}$ at $55^{\circ} \mathrm{C}, 30 \mathrm{sec}$ at $72^{\circ} \mathrm{C}$. Takara Taq polymerase or Takara Ex Taq polymerase were used for amplification. The products of nine SSR loci were electrophoresed in $6 \%$ polyacrylamide gel to detect the variation in length. Since Matsuoka et al. (2009) reported that chloroplast haplotypes of Ae. tauschii could be distinguished by diallelic polymorphisms in four SSR loci 
(WCt6, 10, 17-18, 24) and two intergenic spacer regions, the PCR products of the six loci were sequenced [16]. The PCR products were purified using Wizard SV Gel and PCR Clean-Up System (Promega) and sequenced via DNA sequencing service, eurofins Genomics.

\subsection{AFLP Analysis}

To clarify the phylogenetic relationship of NCT collection, AFLP analyses were carried out. Although we used total DNA for the AFLP analyses, it can be regarded that the results represent the nuclear DNA-based genetic variation because most of DNA in the whole genome is nuclear DNA whereas the proportion of organelle DNAs is extremely small. Five primer sets (E-TGTC \& M-GTA, E-CTGA \& M-GTA, E-AGCG \& M-CCA, E-ATAT \& M-ACC and E-ATAT \& $\mathrm{M}$-CCA) were used for selective amplification, in which $\mathrm{E}$ and $\mathrm{M}$ mean the common sequences for EcoRI and $M s e I$ digested adapter annealing sites, respectively. Takara Taq polymerase was used for the amplifications. The amplified products were electrophoresed in $6 \%$ acrylamide gel and visualized by silver staining. The detailed experimental procedure was following the description in Sasanuma et al. (2002) [25]. After manually scoring the bands, genetic distance using DICE index (1-proportion of sharing bands) were calculated for all the combination pair of the accessions. A Neighbor-Joining phylogenetic tree was reconstructed using PAUP version 4.0b10 [26].

\section{Results}

\subsection{Morphological Characters}

The morphological characteristics are shown in Table 3. The traits related to glume showed about 1.3 - 1.6 times difference between the minimum and maximum values. The maximum values of glume width $(3.87 \mathrm{~mm})$, glume length $(7.11 \mathrm{~mm})$ and glume height $(1.37 \mathrm{~mm})$ were observed in NCT3. This accession also had the largest value in grain width. On the other hand, NCT2 showed the minimum values in glume length $(5.34 \mathrm{~mm})$, glume height $(0.84 \mathrm{~mm})$, spikelet length, grain width and grain length. For all the measurement, the difference between the maximum and the minimum values are statistically significant at $0.1 \%$ level. Generally three values representing glume size, i.e., glume width, glume length and glume height, and spikelet length and grain width showed positive correlations, therefore the features indicated by these five values can be regarded as spikelet size. Three accessions NCT1, NCT15 and NCT16 collected in Stavropol Province and northern part of Degestan had smaller spikelets than the accessions collected around Derbent. There was an exception of NCT2 that was collected in Derbent but had small spikelets. The principal component analysis based on the five spikelet size related traits mentioned above indicated an apparent differentiation of these accessions (Figure 2). NCT14 collected in northern part of Dagestan showed average size of glume but spikelet length and grain width were relatively small. Thus NCT14 somewhat had the feature of 
Table 3. Morphological characterization of 16 NCT accessions.

\begin{tabular}{|c|c|c|c|c|c|c|c|c|c|c|c|c|c|c|c|c|c|c|}
\hline \multirow{2}{*}{$\begin{array}{c}\text { Accession } \\
\text { NCT1 }\end{array}$} & \multicolumn{2}{|c|}{$\begin{array}{c}\text { Glume width } \\
\text { (GW) }\end{array}$} & \multicolumn{2}{|c|}{$\begin{array}{l}\text { Glume length } \\
\text { (GL) }\end{array}$} & \multicolumn{2}{|c|}{ GL/GW } & \multicolumn{2}{|c|}{ Glume height } & \multicolumn{2}{|c|}{$\begin{array}{l}\text { Spikelet } \\
\text { length }\end{array}$} & \multicolumn{2}{|c|}{ Awn length } & \multicolumn{2}{|c|}{ Grain width } & \multicolumn{2}{|c|}{ Grain length } & \multirow{2}{*}{$\begin{array}{c}\begin{array}{c}\text { Spikelet } \\
\text { color }^{\mathrm{a}}\end{array} \\
\text { bright }\end{array}$} & \multirow{2}{*}{$\begin{array}{c}\text { Glume } \\
\text { hair } \\
-\end{array}$} \\
\hline & 2.83 & $* * *$ & 5.66 & $* * *$ & 2.02 & * & 0.92 & $* *$ & 7.96 & $* * *$ & 11.39 & $* * *$ & 1.92 & $* * *$ & 4.49 & $* *$ & & \\
\hline NCT2 & 2.69 & $* * *$ & 5.34 & $* * *$ & 2.00 & $* *$ & 0.84 & $* * *$ & 7.12 & $* * *$ & 7.74 & $* * *$ & 1.77 & $* * *$ & 3.35 & $* * *$ & bright & - \\
\hline NCT3 & 3.87 & & 7.11 & & 1.84 & $* * *$ & 1.37 & & 11.28 & & 12.23 & $* *$ & 2.68 & & 5.03 & & bright & - \\
\hline NCT4 & 3.16 & $* * *$ & 6.59 & & 2.10 & * & 1.23 & & 10.30 & & 11.02 & $* * *$ & 2.31 & * & 4.79 & & bright & - \\
\hline NCT5 & 3.42 & $* *$ & 7.10 & & 2.08 & $* *$ & 1.06 & & 11.34 & & 12.65 & $* *$ & 2.65 & & 5.38 & & $\begin{array}{c}\text { dark } \\
\text { (mixed) }\end{array}$ & - \\
\hline NCT6 & 3.31 & $* * *$ & 6.20 & $* *$ & 1.87 & $* * *$ & 1.17 & & 7.81 & $* * *$ & 8.10 & $* * *$ & 2.27 & * & 4.53 & * & bright & - \\
\hline NCT7 & 3.35 & * & 6.56 & & 1.98 & $* *$ & 1.18 & & 8.81 & * & 16.46 & & 2.39 & & 5.16 & & bright & + \\
\hline NCT8 & 3.59 & & 7.03 & & 1.96 & $* * *$ & 1.13 & & 9.09 & & 8.81 & $* * *$ & 2.27 & & 4.81 & & dark & - \\
\hline NCT9 & 3.58 & * & 6.71 & * & 1.88 & $* * *$ & 1.31 & & 9.29 & * & 8.99 & $* * *$ & 2.53 & & 5.23 & & bright & - \\
\hline NCT10 & 3.29 & $* *$ & 6.60 & & 2.02 & $* *$ & 1.14 & * & 9.70 & & 24.25 & & 2.28 & * & 5.39 & & dark & - \\
\hline NCT11 & 3.16 & $* * *$ & 6.61 & * & 2.09 & $* *$ & 1.18 & & 9.31 & * & 13.05 & $* *$ & 2.49 & & 5.13 & & dark & - \\
\hline NCT12 & 2.88 & $* * *$ & 6.30 & $* *$ & 2.20 & & 1.16 & & 9.01 & * & 21.18 & * & 2.21 & $* *$ & 5.04 & & $\begin{array}{c}\text { dark } \\
\text { (mixed) }\end{array}$ & - \\
\hline NCT13 & 3.23 & $* *$ & 6.28 & & 1.98 & & 1.27 & & 8.93 & * & 19.40 & & 2.30 & * & 4.61 & * & dark & + \\
\hline NCT14 & 3.26 & $* * *$ & 6.64 & & 2.04 & $* * *$ & 1.16 & & 8.68 & $* *$ & 7.21 & $* * *$ & 2.01 & $* * *$ & 3.85 & $* * *$ & bright & - \\
\hline NCT15 & 2.55 & $* * *$ & 5.60 & $* * *$ & 2.20 & * & 0.91 & $* * *$ & 7.13 & $* * *$ & 7.54 & $* * *$ & 1.78 & $* * *$ & 4.05 & $* * *$ & bright & - \\
\hline NCT16 & 2.64 & $* * *$ & 6.29 & $* *$ & 2.38 & & 0.91 & $* * *$ & 7.48 & $* * *$ & 4.79 & $* * *$ & 1.83 & $* * *$ & 4.34 & $* * *$ & bright & - \\
\hline Average & 3.18 & & 6.41 & & 2.04 & & 1.12 & & 8.95 & & 12.18 & & 2.23 & & 4.70 & & & \\
\hline $\begin{array}{l}\text { Standard } \\
\text { deviation }\end{array}$ & 0.36 & & 0.50 & & 0.13 & & 0.15 & & 1.25 & & 5.36 & & 0.28 & & 0.56 & & & \\
\hline
\end{tabular}

All units of quantitative traits are in millimeters. Maximum and minimum values are shown in red and blue, respectively. Statistical significance for difference from the maximum value is indicated on the right. ${ }^{*},{ }^{* *}$ and ${ }^{* * *}$ mean significantly different at $5 \%, 1 \%$ and $0.1 \%$ level by t-test, respectively. a: Dark and bright spikelets were mixed in NCT5 and NCT12.

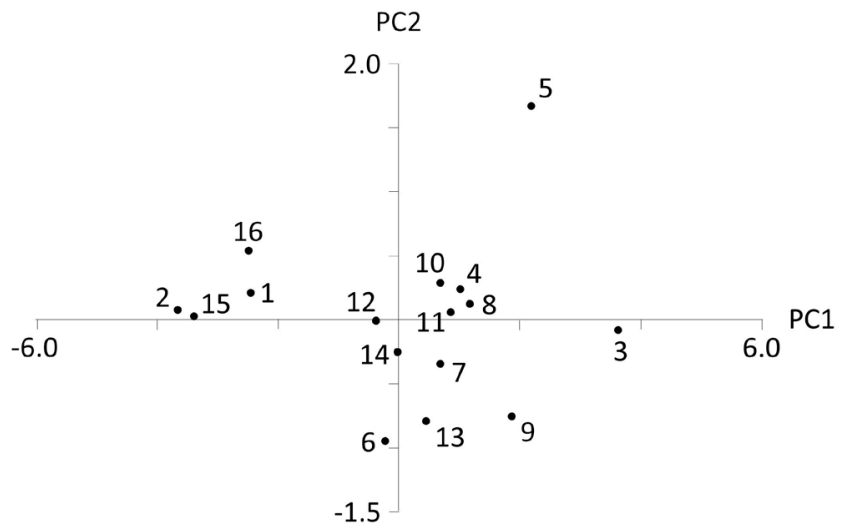

Figure 2. Principal Component Analysis of five spikelet size related traits, glume width, glume length, glume height, spikelet length and grain width. The contribution ratio of PC1 and PC2 were $84.01 \%$ and $7.44 \%$, respectively. The numbers in the graph means NCT numbers. 
northern part accessions. Awn length and grain length exhibited their own tendency. With respect to the qualitative traits, two accessions NCT7 and NCT13 had hairy awns. Six of 16 accessions had dark colored spikes. In addition, one accession NCT2 flowered in the pot without vernalization, suggesting that this accession has spring type heading trait and the remaining are winter type.

The ratio of glume length and glume width (GL/GW) is the key character to distinguish two subspecies. In this study the GL/GW ratio were ranged in 1.84 2.38. In the previous study the GL/GW ratio for subspecies tauschii and strangulata are around 2.0 and 1.2, respectively [16]. Thus all the 16 NCT accessions are categorized into ssp. tauschii.

\subsection{Variation in Chloroplast SSR Loci}

Among the nine chloroplast SSR loci, eight exhibited length polymorphism in polyacrylamide gel electrophoreses (Figure 3 and Table 4). Six loci showed dimorphism among which WCt4, 6, 10 and 12 showed an identical pattern of separation, that is, NCT1, 2, 6, 14, 15, 16 and the others, and WCt8 and 24 showed a different pattern of separation, that is, NCT6 and the others. WCt 5 exhibited three types of bands distinguishing NCT1, 2, 14, 15, 16 and NCT6 and the others. WCt17-18 is the most variable loci having detected four types of bands distinguishing NCT1, 6, 15 and NCT 2, 13, 14 and NCT16 and the others. WCt1 was only the loci monomorphic. The average number of Nei's gene diversity [27] was 0.358 . Based on the polymorphisms detected in the chloroplast SSR loci, 16 NCT accessions were classified into eight haplotypes. The relationship of the haplotypes is shown in Figure 4. Generally eight haplotypes can be separated into three groups. NCT6 formed a single separated group. Five accessions NCT $1,2,14,15$ and 16 collected in the northern part of North Caucasia with an exception of NCT2 formed another group. The remaining ten accessions formed the most major group in which nine accessions had an identical haplotype and NCT13 was different from them by one locus. Hence as well as the spikelet size,

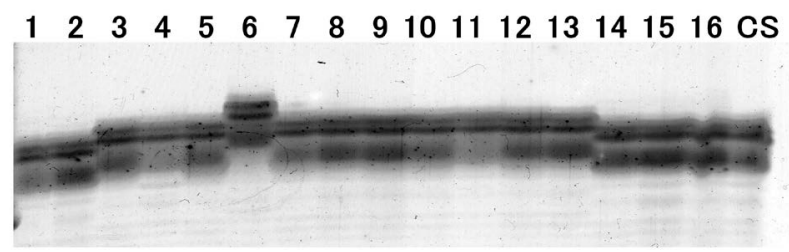

(a)

$\begin{array}{lllllllllllllllll}1 & 2 & 3 & 4 & 5 & 6 & 7 & 8 & 9 & 10 & 11 & 12 & 13 & 14 & 15 & 16 & \mathrm{CS}\end{array}$

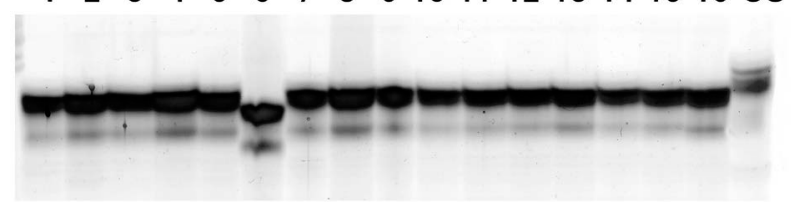

(b)

Figure 3. Profiles of polyacrylamide gel electrophoresis of (a) WCt5 and (b) WCt24. 
Table 4. Chloroplast SSR polymorphism detected among 16 NCT accessions.

\begin{tabular}{|c|c|c|c|c|c|c|c|c|c|c|c|c|c|c|c|c|c|c|c|c|}
\hline \multirow[b]{2}{*}{ Locus } & \multicolumn{17}{|c|}{ Length in bp compared to T. aestivum cv. Chinese Spring (CS) } & \multirow{2}{*}{$\begin{array}{c}\text { Repeat } \\
\text { number } \\
\text { in CS }\end{array}$} & \multirow{2}{*}{$\begin{array}{c}\text { Number } \\
\text { of } \\
\text { Alleles }\end{array}$} & \multirow{2}{*}{$\begin{array}{c}\text { Gene } \\
\text { diversity }\end{array}$} \\
\hline & $\begin{array}{l}\vec{E} \\
\text { Z }\end{array}$ & $\begin{array}{l}\tilde{U} \\
z \\
z\end{array}$ & $\begin{array}{l}\hat{\varphi} \\
z\end{array}$ & $\begin{array}{l}\stackrel{+}{\leftrightarrows} \\
\text { Z }\end{array}$ & $\begin{array}{l}\qquad 0 \\
\qquad \\
z\end{array}$ & $\begin{array}{l}0 \\
\ddots \\
z\end{array}$ & $\begin{array}{l}\hat{\theta} \\
\text { Z }\end{array}$ & $\begin{array}{l}\infty \\
\biguplus \\
z\end{array}$ & $\begin{array}{l}\stackrel{\ominus}{\vartheta} \\
z\end{array}$ & 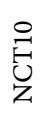 & $\begin{array}{l}\overrightarrow{\vec{G}} \\
\overrightarrow{\mathrm{z}}\end{array}$ & $\stackrel{\stackrel{\Xi}{G}}{\underset{Z}{Z}}$ & $\begin{array}{l}\stackrel{m}{\mid} \\
z\end{array}$ & $\begin{array}{l}\vec{G} \\
\stackrel{\vec{U}}{Z}\end{array}$ & $\begin{array}{l}\stackrel{n}{E} \\
\stackrel{\vec{U}}{Z}\end{array}$ & $\begin{array}{l}0 \\
\stackrel{⿹}{\mid} \\
z\end{array}$ & $\tilde{3}$ & & & \\
\hline WCt1 & 0 & 0 & 0 & 0 & 0 & 0 & 0 & 0 & 0 & 0 & 0 & 0 & 0 & 0 & 0 & 0 & 0 & (A) 10 & 1 & 0.000 \\
\hline WCt4 & -1 & -1 & 0 & 0 & 0 & -1 & 0 & 0 & 0 & 0 & 0 & 0 & 0 & -1 & -1 & -1 & 0 & $(\mathrm{~T}) 11$ & 2 & 0.469 \\
\hline WCt5 & 0 & 0 & 1 & 1 & 1 & 2 & 1 & 1 & 1 & 1 & 1 & 1 & 1 & 0 & 0 & 0 & 0 & (A) 10 & 3 & 0.508 \\
\hline WCt6 & -1 & -1 & -2 & -2 & -2 & -1 & -2 & -2 & -2 & -2 & -2 & -2 & -2 & -1 & -1 & -1 & 0 & (C) 10 & 2 & 0.469 \\
\hline WCt8 & -1 & -1 & -1 & -1 & -1 & 0 & -1 & -1 & -1 & -1 & -1 & -1 & -1 & -1 & -1 & -1 & 0 & $(\mathrm{~T}) 10$ & 2 & 0.117 \\
\hline WCt10 & 1 & 1 & 2 & 2 & 2 & 1 & 2 & 2 & 2 & 2 & 2 & 2 & 2 & 1 & 1 & 1 & 0 & (A) 12 & 2 & 0.469 \\
\hline WCt12 & -1 & -1 & 0 & 0 & 0 & -1 & 0 & 0 & 0 & 0 & 0 & 0 & 0 & -1 & -1 & -1 & 0 & (T) 10 & 2 & 0.469 \\
\hline WCt17-18 & 0 & -1 & -2 & -2 & -2 & 0 & -2 & -2 & -2 & -2 & -2 & -2 & -1 & -1 & 0 & 1 & 0 & $(\mathrm{~T}) 11$ & 4 & 0.609 \\
\hline WCt24 & -1 & -1 & -1 & -1 & -1 & -2 & -1 & -1 & -1 & -1 & -1 & -1 & -1 & -1 & -1 & -1 & 0 & (A) 14 & 2 & 0.117 \\
\hline Average & & & & & & & & & & & & & & & & & & & 2.22 & 0.358 \\
\hline
\end{tabular}

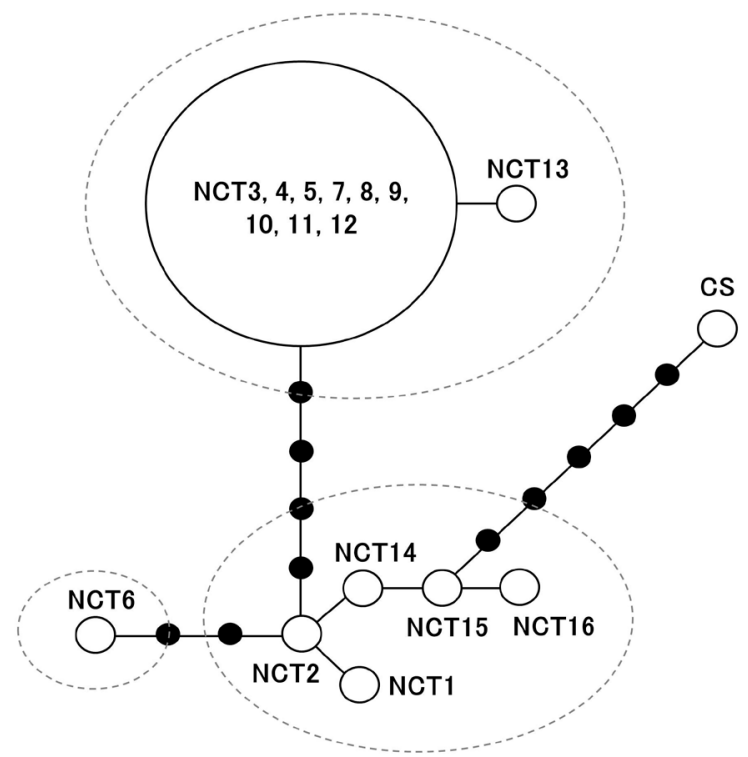

Figure 4. Haplotype network based on the chloroplast SSR polymorphism. Size of the circles reflects the number of accessions. Black solid circles indicate deduced hypothesized haplotypes.

chloroplast SSR variation also divided NCT accessions by collection sites, that is, the northern part of North Caucasia and around Derbent with a unique separation of NCT6.

To determine the chloroplast haplogroup of NCT accessions, sequences of the four SSR loci and two IGS regions were determined. Matsuoka et al. (2009) [16] reported genetic resources of Ae. tauschii can be classified into 18 chloroplast haplogroups based on diallelic sequence polymorphism (nucleotide substitutions and indels) at 21 diagnostic sites. The comparison of the sequences at the 21 
diagnostic sites indicated that all the 16 NCT accessions belong to HG7 that is the most common haplotype in the species. The sequences of the 16 NCT accessions are basically the same except for the SSR repeat number but a single nucleotide substitution was detected at 278th nucleotide position at $\operatorname{trnL}-F$ IGS region. At this site consensus sequences is T but six accessions NCT1, 2, 3, 14, 15 and 16 had A. Since Matsuoka et al. (2009) [16] ignored multiallelic polymorphisms (more than three types at a site) for genotyping, this site may be multiallelic in the species, but if not, the chloroplast haplotype of these six accessions is a new derivative of HG7.

\subsection{AFLP Analysis}

Totally 274 bands were scored in the five primer combinations. Based on the AFLP detected, a Neighbor-Joining phylogenetic tree for 39 accessions of Ae. tauschii was reconstructed (Figure 5). There are two major clusters A and B in the tree. This clustering generally well fits with the classification reported in the previous study [19]. According to the positions of the previously used accessions, it is considered that clusters A and B correspond to groups A and C in Sohail et al. (2012) [19], respectively. The accession of minor group B in the previous study is located on the outgroup position of cluster B in the present study that is also consistent with the previous result. Cluster A in this study is considered to be Eurasian wide genepool since it covered the whole distribution of the species from Turkey to China, in other words this is Tauschii genepool reported in Dvorak et al. (1998) [14]. Cluster B is the Caucasia and Caspian coast limited genepool that is equivalent to the Strangulata genepool reported in Dvorak et al. (1998) [14]. The four accessions of ssp. strangulata formed a subcluster in this cluster. The 16 NCT accessions were present in both major clusters. Five accessions NCT1, 2, 14, 15, 16 collected in the northern part of North Caucasia with an exception NCT2 are located in cluster A and the other in cluster B. This division of the 16 NCT accessions into two groups is generally consistent with spikelet size and chloroplast SSR variation.

\section{Discussion}

In this study, 16 accessions of Ae. tauschii newly collected from North Caucasia in 2010 were genetically characterized. Chloroplast and AFLP based nuclear DNA analyses indicated a distinct separation of the 16 NCT accessions into two groups. One consists of NCT1, 2, 14, 15 and 16 mainly collected from Stavropol Province and the northern part of Dagestan that can be called the northern part of North Caucasia. The other is composed of the remaining 11 accessions collected from Derbent in the southern border of North Caucasia adjacent to Azerbaijan, Transcaucasia. NCT2, an exception for this geographical grouping, was collected in Derbent but classified into the northern part group. It is possible that this contradiction was due to a recent introgression via human activity since NCT2 was collected on a roadside. As well as molecular analyses, morphological 


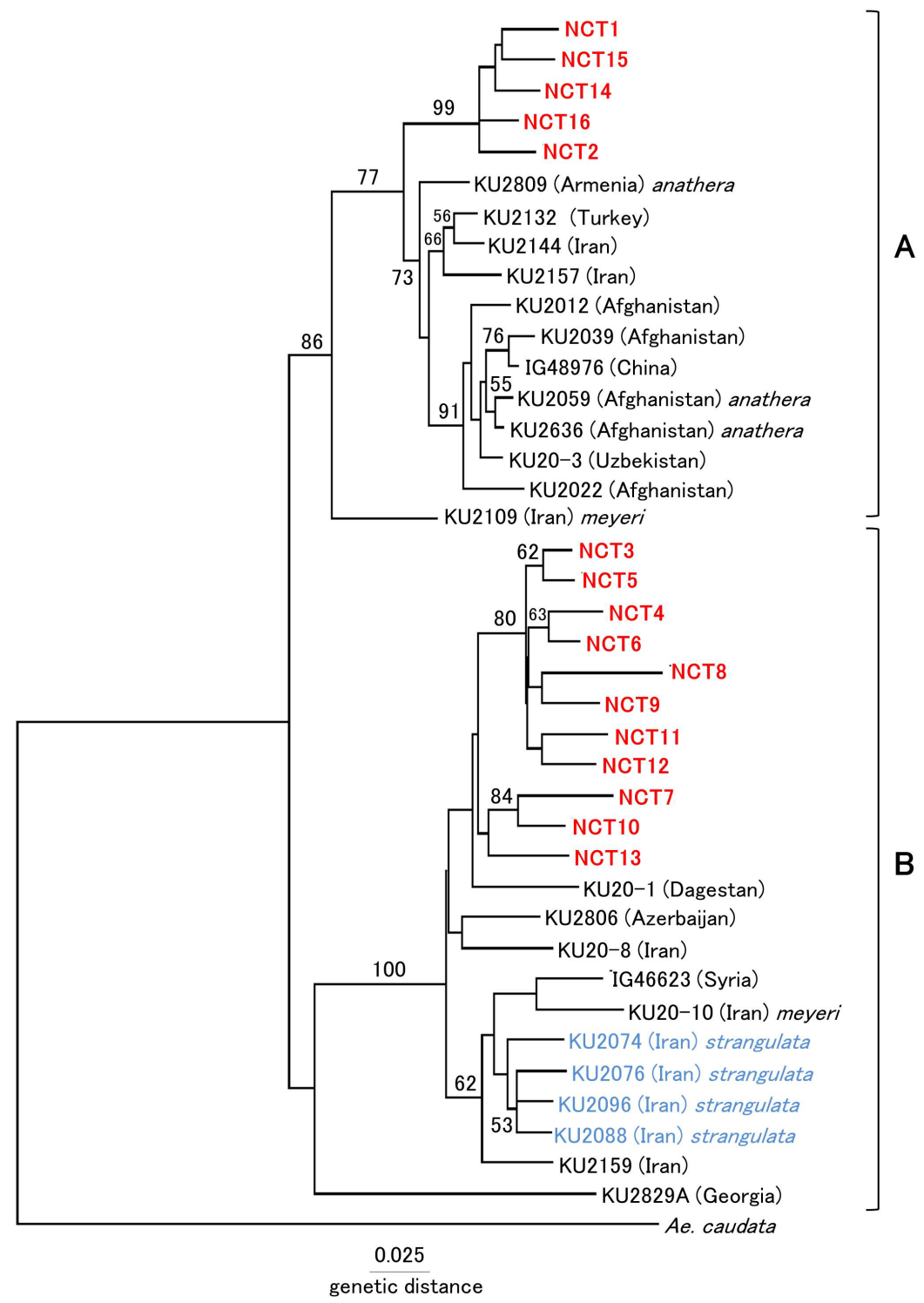

Figure 5. Neighbor-Joining tree reconstructed based on AFLP. Varieties anathera, meyeri and strangulata are indicated on the right of the accession number. NCT accessions and ssp. strangulata are shown in red and blue, respectively. More than 50\% bootstrap probabilities obtained from 1,000 replicates are shown beside the branches.

evaluation also showed a tendency of differentiation in spikelet size between the northern part group and Derbent group although the separation is not so obvious. This difference could be caused by the genetic differentiation but it is also possible that the environmental condition generated it because we compared the spikelets originally collected in North Caucasia.

The AFLP analysis revealed that the two groups in NCT accessions are representing the two major genepool in entire species of Ae tauschii reported in several previous studies [14] [18] [19]. The northern part group corresponds to Eurasian wide genepool namely Tauschii genepool and the Derbent group to Caucasia and Caspian coast limited genepool namely Strangulata genepool. Since 
all the 16 accessions had vertically elongated rectangle glumes based on GL/GW ratio, they are categorized into ssp. tauschii not ssp. strangulata morphologically. This result is supported by the fact that the Derbent group NCT accessions are separately located from the subcluster of ssp. strangulata in cluster B. Thus, the NCT accessions in cluster B are belonging to ssp. tauschii morphologically but Strangulata genepool genetically as several Transcaucasian accessions reported in previous study by Dvorak et al. [14]. These results indicate that the southern part of North Caucasia is a margin of the distribution of Strangulata genepool, in other words, the end of the center of diversity of Ae. tauschii. From the observation during our exploration in North Caucasia, the area around Derbent certainly has richer diversity for Aegilops than the northern part. Ae. tauschii and another tetraploid Ae. cylindrica seemed to be dominant grass species in the area and three other tetraploid Aegilops species, Ae. triuncialis, Ae. biuncialis and Ae. triaristata were also found. On the other hand, in the northern part of North Caucasia Aegilops were not so often discovered. Ae. cylindrica was relatively common but Ae. tauschii was rare and other Aegilops species could seldom found in the northern part of North Caucasia.

The results of this study indicated that the entire level of genetic variation in NCT accessions was considerably high. For example, the gene diversity for 16 NCT accessions based on nine chloroplast SSR loci was 0.358 that is almost equivalent to 0.375 for 63 accessions of Ae. tauschii covering the major part of the species distribution reported in Matsuoka et al. (2005) [15]. This high level of diversity in North Caucasia is, however, due to the presence of two major genepool. The variation in each group is not necessarily high. The chloroplast genotyping showed that all the NCT accessions belonged to HG7 the major haplogroup of Ae. tauschii found in the entire distribution. This result suggests that the level of diversity in North Caucasia is less than in Transcaucasia. Even if so, however, we would like to emphasis that North Caucasian Ae. tauschii includes a level of variation and potential of unique genetic traits, for example, variation in glume hair and spike color, and a unique chloroplast genotype detected in NCT6. The large spikelet and grain size observed in the Derbent group suggests the usability for future breeding of these genetic resources. It is noteworthy that the largest size of spikelet detected in NCT3 is at the maximum level for ssp. tauschii.

Ae. tauschii is one of the most important wild genetic resources for wheat genetics and breeding since it is the $\mathrm{D}$ genome donor of bread wheat. As represented by whole genome sequencing of Ae. tauschii [28], the recent advance of molecular researches has accumulated the genetic information and enlarged the availability to utilize wild genetic resources for wheat improvement, therefore the importance of genetic resources is also increasing nowadays. Ae. tauschii is one of the wild species that has been extensively collected but North Caucasia had been a missing zone. We must note that previous studies also used a few accessions collected in North Caucasia but those were mainly collected 
around Derbent [16] [18] [19] [20] [21]. Thus the northern part group used in this study is really new materials for diversity study of Ae. tauschii. Needless to say, it is important for diversity analysis to cover entire species distribution. The recent studies indicated the sublineage division within the major two genepool of Ae. tauschii that is generally related to the geographical distribution [18] [20] [21]. In this study we genetically characterized the new materials collected in North Caucasia where only limited samples have been analyzed. The present study is the first report of a series of evaluation studies on genetic resources of North Caucasian Ae. tauschii. Currently we are conducting more practical evaluation concerning bread-making related traits and it is suggested that some of them might have suitable traits (data not shown). It must be emphasized that the basic morphological and molecular diversity evaluation carried out in this study can be a foundation for using the genetic resources for more practical purpose. We believe that the results of this study added novel valuable information to elucidate the genetic diversity in Ae. tauschii and should be helpful for future wheat improvement.

\section{Acknowledgements}

We thank to Dr. Sergey Alexanian who was vice director for foreign relations of the N.I. Vavilov Institute for his arrangement of this international collaboration. All the authors express sincere condolences for his sudden passing away during the collaboration. We also thank to the staffs of the branch stations of Vavilov Institute in North Caucasia, especially in Dagestan station, for their kind support during the collection mission. This study was supported by the international exchange program between Japan and Russia, Japan Society for the Promotion of Science.

\section{References}

[1] Kihara, H. (1944) Discovery of the DD-Analyser, One of the Ancestors of Triticum vulgare. Agriculture and Horticulture, 19, 13-14. (In Japanese)

[2] McFadden, E.S. and Sears, E.R. (1946) The Origin of Triticum spelta and Its Free-Threshing Hexaploid Relatives. Journal of Heredity, 37, 107-116. https://doi.org/10.1093/oxfordjournals.jhered.a105594

[3] van Slageren, M.W. (1994) Wild Wheats: A Monograph of Aegilops L. and Amblyopyrum (Jaub. \& Spach) Eig (Poaceae). Joint Publication of ICARDA, Aleppo, Syria and Wageningen Agricultural University, The Netherlands.

[4] Lagudah, E.S. and Halloran, G.M. (1988) Phylogenetic Relationships of Triticum tauschii the D genome Donor to Hexaploid Wheat. 1. Variation in HMW Subunits of Glutenin and Gliadins. Theoretical and Applied Genetics, 75, 592-598. https://doi.org/10.1007/BF00289125

[5] Matsuoka, Y., Takumi, S. and Kawahara, T. (2008) Flowering Time Diversification and Dispersal in Central Eurasian Wild Wheat Aegilops tauschii Coss.: Genealogical and Ecological Framework. PLoS ONE, 3, e3138. http://journals.plos.org/plosone/article?id=10.1371/journal.pone.0003138 https://doi.org/10.1371/journal.pone.0003138 
[6] Innes, R.L. and Kerber, E.R. (1994) Resistance to Wheat Leaf Rust and Stem Rust in Triticum tauschii and Inheritance in Hexaploid Wheat of Resistance Transferred from T. tauschii. Genome, 37, 813-822. https://doi.org/10.1139/g94-116

[7] Gororo, N.N., Eagles, H.A., Eastwood, R.F., Nicolas, M.E. and Flood, R.G. (2002) Use of Triticum tauschiito Improve Yield of Wheat in Low-Yielding Environments. Euphytica, 123, 241-254. https://doi.org/10.1023/A:1014910000128

[8] Sohail, Q., Inoue, T., Tanaka, H., Eltayeb, A.E., Matsuoka, Y. and Tsujimoto, H. (2011) Applicability of Aegilops tauschii Drought Tolerance Traits to Breeding of Hexaploid Wheat. Breeding Science, 61, 347-357. https://doi.org/10.1270/jsbbs.61.347

[9] Eig A (1929) Monographisch-kritische Übersicht der GatteungAegilops. Repertorium Specierum Novarum Rgni Vegetabilis. [Monographically Critical Review of the Genus Aegilops. Repertory Specierum Novarum Rgni Vegetabilis.] Beihefte, 55, 1-228. (In Germany)

[10] Hammer, K. (1980) Vorarbeiten zur monographischen Darstellung von Wildpflanzensortimenten: Aegilops L. [Preliminary Work on the Monographic Representation of Wild Plant Species: Aegilops L.] Die Kulturpflanze, 28, 33-180. (In Germany) https://doi.org/10.1007/BF02014641

[11] Jaaska, V. (1978) NADP-Dependent Aromatic Alcohol Dehydrogenase in Polyploid Wheats and Their Relatives. On the Origin and Phylogeny of Polyploid Wheats. Theoretical and Applied Genetics, 53, 209-217. https://doi.org/10.1007/BF00277370

[12] Jaaska, V. (1980) Electrophoretic Survey of Seedling Esterases in Wheats in Relation to Their Phylogeny. Theoretical and Applied Genetics, 56, 273-284. https://doi.org/10.1007/BF00282570

[13] Nishikawa, K., Furuta, Y. and Wada, T. (1980) Genetic Studies on Alpha-Amylase Isozymes in Wheat. III. Intraspecific Variation in Aegilops squarrosa and Birthplace of Hexaploid Wheat. Japanese Journal of Genetics, 55, 325-336. https://doi.org/10.1266/jjg.55.325

[14] Dvorak, J., Luo, M.C., Yang, Z.L. and Zhang, H.B. (1998) The Structure of the Aegilopstauschii Genepool and the Evolution of Hexaploid Wheat. Theoretical and Applied Genetics, 97, 657-670. https://doi.org/10.1007/s001220050942

[15] Matsuoka, Y., Mori, N. and Kawahara, T. (2005) Genealogical Use of Chloroplast DNA Variation for Intraspecific Studies of Aegilops tauschii Coss. Theoretical and Applied Genetics, 111, 265-271. https://doi.org/10.1007/s00122-005-2020-x

[16] Matsuoka, Y., Nishioka, E., Kawahara, T. and Takumi, S. (2009) Genealogical Analysis of Subspecies Divergence and Spikelet-Shape Diversification in Central Eurasian Wild Wheat Aegilops tauschii Coss. Plant Systematics and Evolution, 279, 233-244. https://doi.org/10.1007/s00606-009-0159-7

[17] Sasanuma, T., Chabane, K., Endo, T.R. and Valkoun, J. (2004) Characterization of Genetic Variation in and Phylogenetic Relationships among Diploid Aegilops Species by AFLP: Incongruity of Chloroplast and Nuclear Data. Theoretical and Applied Genetics, 108, 612-618. https://doi.org/10.1007/s00122-003-1485-8

[18] Mizuno, N., Yamasaki, M., Matsuoka, Y., Kawahara, T. and Takumi, S. (2010) Population Structure of Wild Wheat D-Genome Progenitor Aegilops tauschii Coss: Implications for Intraspecific Lineage Diversification and Evolution of Common Wheat. Molecular Ecology, 19, 999-101. https://doi.org/10.1111/j.1365-294X.2010.04537.x

[19] Sohail, Q., Shehzad, T., Kilian, A., Eltayeb, A.E., Tanaka, H. and Tsujimoto, H. (2012) Development of Diversity Array Technology (DArT) Markers for Assessment of 
Population Structure and Diversity in Aegilops tauschii. Breeding Science, 62, 38-45. https://doi.org/10.1270/jsbbs.62.38

[20] Wang, J., Luo, M.C., Chen, Z., You, F.M., Wei, Y., Zheng, Y. and Dvorak, J. (2013) Aegilopstauschii Single Nucleotide Polymorphisms Shed Light on the Origins of Wheat Dgenome Genetic Diversity and Pinpoint the Geographic Origin of Hexaploid Wheat. New Phytologist, 198, 925-937. https://doi.org/10.1111/nph.12164

[21] Matsuoka, Y., Takumi, S. and Kawahara, T. (2015) Intraspecific Lineage Divergence and Its Association with Reproductive Trait Change during Species Range Expansion in Central Eurasian Wild Wheat Aegilops tauschii Coss. (Poaceae). BMC Evolutionary Biology, 15, 213.

https://bmcevolbiol.biomedcentral.com/articles/10.1186/s12862-015-0496-9 https://doi.org/10.1186/s12862-015-0496-9

[22] Murray, M.G. and Thompson, W.F. (1980) Rapid Isolation of Highmolecular-Weight Plant DNA. Nucleic Acids Research, 8, 4321-4325.

https://doi.org/10.1093/nar/8.19.4321

[23] Ishii, T., Mori, N. and Ogihara, Y. (2001) Evaluation of Allelic Diversity at Chloroplast Microsatellite Loci among Common Wheat and Its Ancestral Species. Theoretical and Applied Genetics, 103, 896-904. https://doi.org/10.1007/s001220100715

[24] Tabertlet, P., Gielly, L., Pautou, G. and Bouvet, J. (1991) Universal Primers for Amplification of Three Non-Coding Regions of Chloroplast DNA. Plant Molecular Biology, 17, 1105-1109. https://doi.org/10.1007/BF00037152

[25] Sasanuma, T., Chabane, K., Endo, T.R. and Valkoun, J. (2002) Genetic Diversity of Wheat Wild Relatives in the Near East Detected by AFLP. Euphytica, 127, 81-93. https://doi.org/10.1023/A:1019941817057

[26] Swofford, D.L. (2002) PAUP. Phylogenetic Analysis Using Parsimony (and Other Methods). Version 4. Sinauer Associates, Sunderland.

[27] Nei, M. (1987) Molecular Evolutionary Genetics. Columbia University Press, New York.

[28] Jia, J., Zhao, S., Kong, X., Li, Y., Zhao, G., He, W., Appels, R., Pfeifer, M., Tao, Y., Zhang, X., et al. (2013) Aegilops tauschii Draft Genome Sequence Reveals a Gene Repertoire for Wheat Adaptation. Nature, 496, 91-95.

https://doi.org/10.1038/nature12028 